\title{
Sequential impact of components of maternal and child health care services on the continuum of care in India
}

\author{
K. S. James ${ }^{1}$, Udaya S. Mishra ${ }^{2}$ (D) Rinju² and Saseendran Pallikadavath ${ }^{3 \star}$ (D) \\ ${ }^{1}$ International Institute for Population Science (IIPS), Mumbai, India, ${ }^{2}$ Centre for Development Studies, Kerala, India and \\ ${ }^{3}$ Portsmouth-Brawijaya Centre for Global Health, Population and Policy, University of Portsmouth, UK \\ *Corresponding author. Email: sasee.pallikadavath@port.ac.uk
}

(Received 28 April 2020; revised 21 January 2021; accepted 2 February 2021; first published online 10 May 2021)

\begin{abstract}
This paper examines the sequential impact of components of maternal and child health care on the continuum of care in India using data from the Indian National Family Health Surveys conducted in 2005-06 and 2015-16. Continuum of care (CoC) for maternal and child health is defined in this paper as the sequential uptake of three key maternal services (antenatal care, institutional delivery and postnatal care for the mother). Women who received all three services were classified as full $\mathrm{CoC}$ recipients. Characteristics odd ratios for achieving $\mathrm{CoC}$ were estimated by mother's place of residence, household wealth status, mother's education, birth order and child full vaccination. Odds ratios were computed to understand the relative impact of each preceding service utilization on the odds of subsequent service uptake. At national level, $30.5 \%$ and $55.5 \%$ of women achieved full $\mathrm{CoC}$ in $2005-06$ and 2015-16, respectively, and the overall progress of $\mathrm{CoC}$ over the 10 -year period was 25.5 percentage points, with significant variation across states and socioeconomic groups. Full CoC improved from $7.5 \%$ to $32.4 \%$ among the poorest women, whereas among the richest women it improved from $70.5 \%$ to $75.1 \%$. Similarly, among uneducated women full $\mathrm{CoC}$ improved from $11.7 \%$ to $35.9 \%$ as against $75.1 \%$ to $80.5 \%$ among educated mothers over the same period. Furthermore, greater $\mathrm{CoC}$ was observed among parity one women. The conditionality between various components of $\mathrm{CoC}$ indicated that at national level the odds of having an institutional delivery with antenatal care were 9 times higher in the earlier period as against 4.5 times higher in the more recent period. Furthermore, women who had institutional deliveries complied more with mother's postnatal care compared with women who did not have institutional deliveries. This again helps increase the likelihood of a child receiving full vaccination.
\end{abstract}

Keywords: Institutional delivery; Continuum of Care; JSY

\section{Introduction}

Globally, despite several years of focused efforts, maternal and child mortality remains a major concern. This is reflected in Goal 3 of the UN Sustainable Development Goals (SDGs), which aims to reduce maternal mortality to a global ratio of less than 70 per 100,000 live births by 2030. It also aims to reduce neonatal mortality to less than 12 per 1000 live births, and end the preventable deaths of newborns and children under 5 years of age. Regardless of this 2015 commitment, in 2017300,000 women died from complications relating to pregnancy and childbirth globally, and about $90 \%$ of these deaths were in low- and middle-income countries. Globally, under-5 mortality fell from 77 deaths per 1000 live births in 2000 to 39 deaths in 2017. The total number of under-5 deaths dropped from 9.8 million in 2000 to 5.4 million deaths in 2017 . About $30 \%$ of these deaths occurred in southern Asia (Unite Nations, 2019). Therefore, to achieve SDG-3, 
significant reductions in maternal, neonatal and under-5 mortality are required in low- and middle-income countries.

In India the maternal mortality ratio declined from 212 per 100,000 live births in 2007-09 to 113 in 2016-18. The decline was from 308 to 161 in the Empowered Action Group (EAG) of states, while in the southern states it was from 127 to 67 and in other states it was from 149 to 83 per 100,000 live births (SRS, 2011, 2020). Under-5 mortality declined from 97 per 1000 live births in 2000 to 39 deaths in 2017 (UNICEF, 2020). Neonatal mortality in India declined from 42 per 1000 live births in 2000 to 20 in 2018.

Clearly, significant reductions in both the maternal mortality ratio and neonatal mortality rate are needed to achieve SDG-3 in India. It is important to further note that about $18 \%$ of global maternal deaths occur in India. Although both maternal and neonatal mortality have been declining in India, their relative global share has remained the same. To improve maternal and neonatal health, the Government of India launched the safe motherhood intervention 'Janani Suraksha Yojana' (JSY) in 2005, implemented by the National Health Mission. The core objective of this has been to increase institutional delivery by increasing the demand for services using cash incentives for women conditional on institutional delivery (MoHFW, 2018a).

Generally, the performance of maternal and child health services is measured individually in terms of the coverage/uptake of antenatal visits, institutional delivery and postnatal visits/ check-ups (Chopra et al., 2009; Mohammad \& Pallikadavath, 2018). In India, coverage of these services has improved substantially over the last few decades. However, improvement in adverse pregnancy outcomes, for instance perinatal mortality, has been slow in all regions except for Central, where is increased from $10.6 \%$ to $16.8 \%$ from $2005-06$ to $2015-16$, and did not achieve the anticipated level needed to reach the SDG-3 targets (in the North $14.3 \%$ to $11.0 \%$, East $13.7 \%$ to $10.0 \%$, North East $17.2 \%$ to $14.2 \%$ and West $23.7 \%$ to $7.2 \%$ ). Antenatal care (ANC) coverage and institutional delivery uptake in $2015-16$ were $83 \%$ and $81 \%$ respectively, but access to postnatal care for mothers and children was substantially lower at $65 \%$ and $37 \%$ respectively (NFHS4). This means that higher coverage with the individual components of service utilization does not ensure that women receive all the essential components (Shibanuma et al., 2018): this deficit is likely to result in persistently poorer health outcomes. Most maternal deaths occur during labour or delivery or in the immediate postpartum period and could be avoided with effective integration of the key services linked to the continuum of care (Iqbal et al., 2017; Rahman et al., 2019). It is important that women and children receive all key services as a continuum to avoid complications that can lead to morbidity and death.

The concept of continuum of care $(\mathrm{CoC})$ for maternal, neonatal and child health $(\mathrm{MNCH})$ incorporates two dimensions, i.e. time and place: for instance, time of pregnancy registration, number of antenatal care (ANC) visits, institutional delivery, mother and child postnatal care within 2 weeks of postpartum and child vaccination. The central idea is that for a better maternal and child health outcome it is important to achieve all the components of $\mathrm{MNCH}$ services. The 'place' dimension of $\mathrm{CoC}$ for $\mathrm{MNCH}$ considers integration of care-giving within the home, the first-level facility and the hospital. This study focused was on the effect of JSY on the coverage of all the services of $\mathrm{CoC}$ - antenatal care, institutional delivery and postnatal care - across the Indian states. A limited attempt was made to understand the effect of JSY in improvement of full CoC coverage in India. Two rounds of National Family Health Survey (NFHS) data (2005-06 and 2015-16) were examined because it is important to understand the pattern of $\mathrm{CoC}$ for maternal and child health in India and the magnitude by which this varies across states and socioeconomic groups in order to take corrective policy measures. It is particularly important in the context of demand-side financing interventions such as JSY to overcome financial barriers to the utilization of maternal health care services among poor women in the country. Given this context, the objectives of this study were: (1) to assess the levels and patterns of $\mathrm{CoC}$ for $\mathrm{MNCH}$ in India and its states; (2) to study the role of mothers' education, household wealth status, place of residence, 
birth order and full vaccination in full CoC; and (3) to understand the impact of each component of $\mathrm{MNCH}$ services on the uptake of subsequent maternal health services to achieve full CoC.

\section{Methods}

The study used data from the NFHS-3 conducted in 2005-06 and NFHS-4 conducted in 2015-16. The sampling procedure for the surveys is explained in detail elsewhere (IIPS \& ICF, 2007, 2017). Briefly, the NFHS adopted a multi-stage stratified design with a sampling frame based on the 2011 census. Primary Sampling Units (PSUs) were villages in rural areas and Census Enumeration Blocks (CEBs) in urban areas. Within each rural stratum, villages were selected from the sampling frame with probability proportional to size (PPS). In urban areas, CEBs were sorted according to the percentage of the Scheduled Caste/Scheduled Tribe population in each CEB, and CEBs were selected with PPS sampling. In every selected rural and urban PSU, a complete household mapping and listing operation was conducted prior to the main survey. Selected PSUs with an estimated number of at least 300 households were segmented into approximately 100-150 households. Two of the segments were randomly selected for the survey using systematic sampling with probability proportional to segment size. In the second stage, in every selected rural and urban cluster, 22 households were randomly selected with systematic sampling.

Information was analysed from all eligible women aged 15-49 from the Woman's Questionnaire of the surveys who were asked questions, among others, on antenatal care, delivery care and postnatal care. The analysis was restricted to the most recent birth of mothers who gave birth within the past 5 years (36,850 for NFHS-3 and 190,898 for NFHS-4). This was due to the time limit in data collected by the NFHS, and since information was recorded for the most recent birth only.

\section{Outcome variable}

A woman who had her delivery in any health facility (public or private) was considered to have had an institutional delivery (ID). This was used as a dependent variable to assess the demand-side financing intervention of the JSY maternal and child health programme, which provides monetary incentives to poor and marginalized mothers to deliver in a health facility (MoHFW, 2018b), and to assess the role of incentivization in shaping compliance with components of continuum of care in maternal and child services.

\section{Correlates}

The CoC elements for maternal and child health services were: antenatal care; postnatal care for the mother (PNC-M), i.e. postpartum check-up within 2 days of delivery by a health professional or Accredited Social Health Activists (ASHAs) or traditional birth attendant; and child full vaccination by 12-23 months by a health professional, ASHA or traditional birth attendant.

Those who had any ANC were considered to be 'ANC recipients'. If a woman had her postnatal check-up within 2 days of delivery, she was considered to be a 'postnatal care recipient' (PNC-M), and children receiving full vaccination at age 12-23 months, i.e. who had received all basic vaccinations vaccines by the time of the survey (according to a vaccination card or the mother's report) were considered to have 'full vaccination'. Basic vaccinations were: at least one dose of BCG vaccine, which protects against tuberculosis, three doses of DPT vaccine, which protects against diphtheria, pertussis (whooping cough), and tetanus, three doses of polio vaccine and one dose of measles vaccine. If a woman received all three services she was considered to have 'full CoC'. 'Partial CoC' was when at least one of the services was not received. Women who received none of these services were considered to have 'no service uptake'. The associations 
of full $\mathrm{CoC}$ with birth order, place of residence, mother's level of education and wealth status of the household were also analysed.

\section{Statistical analysis}

The likelihood a woman having 'full CoC' was represented by characteristic odds ratios (CORs) for the exogenous variables urban-rural place of residence, household wealth quintile, mother's level of education, birth order and full child vaccination. For instance, $p_{i}$ represents the probability of full $\mathrm{CoC}$ with a certain feature $i$ - say, urban residence - which can be denoted as $p_{i \text { (Full coc for characteristics) }}$ and $p_{j}$ represents the probability of full CoC irrespective of any characteristics, denoted by $p_{\text {(Ful CoC for India })}$, and was considered as the reference for ease of comparison and interpretation. Characteristic odds ratios can therefore be interpreted as showing an increased or decreased likelihood of full $\mathrm{CoC}$ compared with overall compliance with full CoC. They are also used in conditional form to understand the relative importance of preceding components of $\mathrm{MNCH}$ on the subsequent components of the continuum of care chain. The computation of the COR is as follows:

$$
\operatorname{Odds}_{i}=\frac{p_{i}}{1-p_{i}}
$$

Similarly, the odds for the Services $p_{i}$ and $p_{j}$ are calculated as:

$$
\operatorname{Odds}_{j}=\frac{p_{j}}{1-p_{j}}
$$

The COR of the Service $p_{i}$ with Service $p_{j}$ is calculated using the formula:

$$
\mathrm{COR}=\frac{\mathrm{Odds}_{i}}{\mathrm{Odds}_{j}}
$$

CORs convey the likelihood of compliance with service $i$ conditioned by the compliance with service ' $j$.' Theoretically the value of a COR varies from zero to infinity.

Logistic regression analysis was used to estimate the association of institutional delivery and other maternal services at the national and state level. The logistic regression model is one of the widely used statistical techniques for the binary dependent variable which provide the valid and reliable regression coefficient adjusting for the study design and confounder. Here, institutional delivery was the binary variable used as the outcome variable. The general equation of the logistic model is:

$$
\begin{gathered}
\operatorname{logit}\left(P_{i}\right)=\alpha+\beta_{1}(\mathrm{ANC})+e_{i} \\
\operatorname{logit}\left(P_{i}\right)=\alpha+\beta_{1}(\text { Postnatal care })+e_{i} \\
\operatorname{logit}\left(P_{i}\right)=\alpha+\beta_{1}(\text { Full vaccination })+e_{i}
\end{gathered}
$$

where $\alpha$ is the intercept. The results of the logistic regression are presented as unadjusted odds ratios (UORs) and the intra-class correlation coefficient (ICC) and variance inflation factor (VIF) were calculated to understand the multicollinearity among the independent variables. Pearson's Chi-squared test, as well as the F-adjusted test statistic, were used to test goodness-of-fit of the model. All analyses were carried out using the STATA 15 software. 
ANC \& ID \& PNC-M (full CoC)

ANC \& ID

Any one service (partial CoC)

No service uptake

PNC-M

ID

ANC

0

10

20

30

40

50

60

70

80

90

-2005-06 $\backsim 2015-16$

Figure 1. Percentage distribution of maternal services in India, 2005-06 and 2015-16. ANC, antenatal care; ID, institutional delivery; PNC-M, postnatal care for the mother.
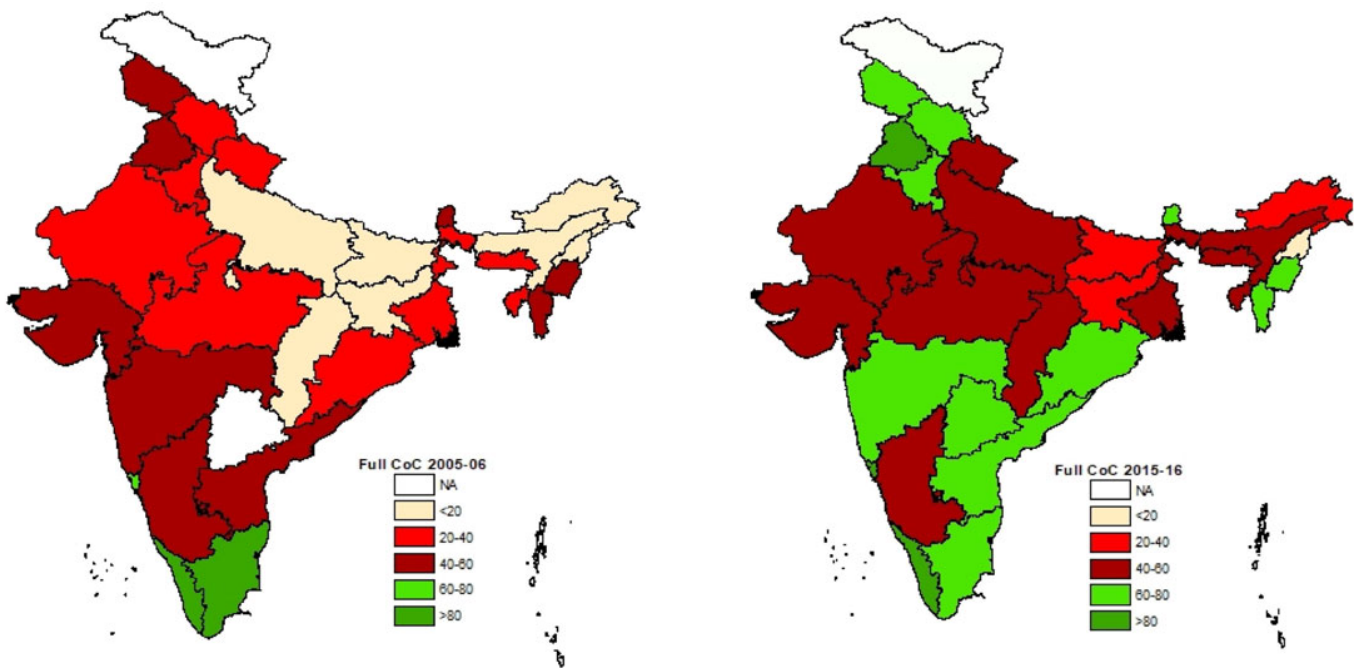

Figure 2. Prevalence of full CoC in Indian states, 2005-06 and 2015-16.

\section{Results}

\section{Pattern of continuum of care from 2005-06 to 2015-16}

Figure 1 illustrates the significant improvement in CoC in India from 2005-06 to 2015-16. India's full $\mathrm{CoC}$ level improved from $30.5 \%$ to $55.5 \%$ over the 10 -year period. Remarkable progress was achieved in institutional delivery, which increased from $39.0 \%$ to $79.0 \%$, and PNC-M, which increased from 37.2\% to 65.1\%. Whereas together ANC and institutional delivery uptake increased from $38.8 \%$ to $71.0 \%$, there was clearly a continuous decline in maternal services uptake moving from antenatal to postnatal care.

The pattern of change in CoC over time differed across states, with the southern states of Tamil Nadu, Kerala and Goa being ahead, even in 2005-06, and the introduction of National Rural Health Mission (NRHM) had made a difference to CoC compliance in the states of Jammu Kashmir, Punjab, Odisha and Maharashtra (Figure 2). On comparing the improvement in full $\mathrm{CoC}$ over time across states (Figure 3), it is apparent that those that had a poor CoC in 


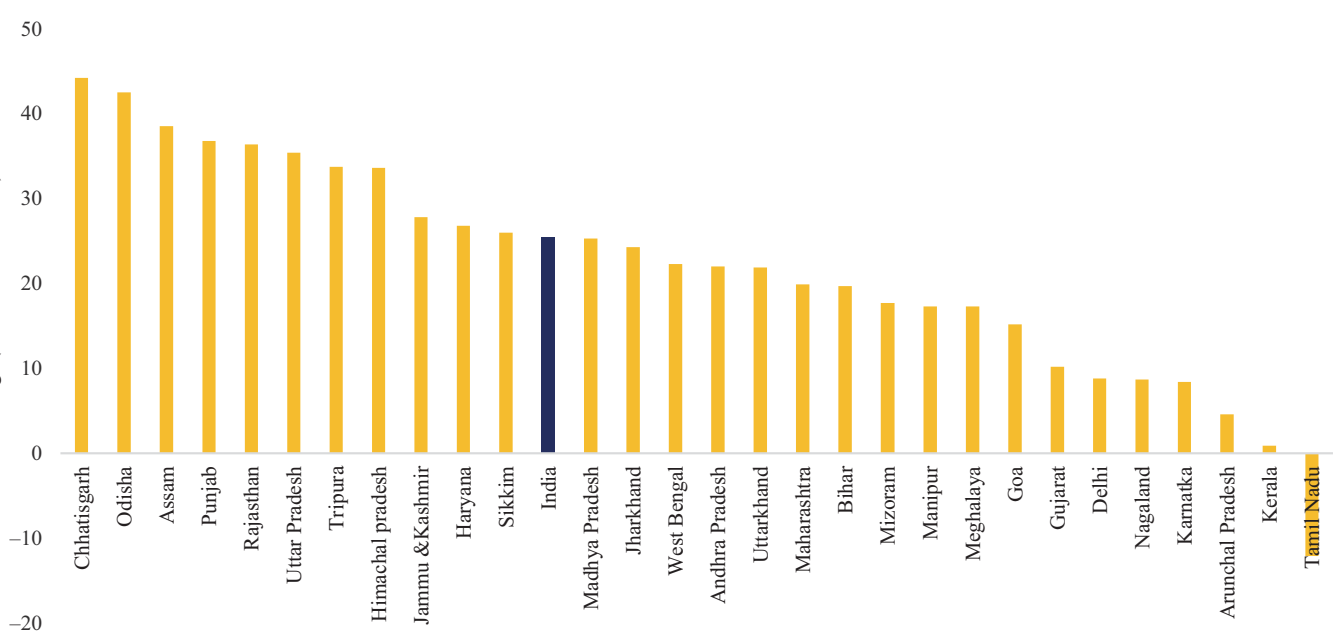

Figure 3. Absolute change of COC from 2005-06 to 2015-16 in India and states.

2005-06 experienced major gains, above the national gain of 25.5\%. All states experienced a gain in level of full $\mathrm{CoC}$, but Chhattisgarh, Odisha, Punjab and Rajasthan experienced phenomenal improvements over the decade.

Phenomenal progress has been made in institutional delivery compared with ANC care and PNC-M (Table 1). However, progress in ANC was also marked for a select set of states where uptake had been poor in 2005-06. To name a few, Uttar Pradesh, Bihar, Jharkhand and Rajasthan experienced a substantial increase in ANC uptake to attain convergence with other states where ANC utilization has risen above $80 \%$. Undoubtedly, there has been a move towards universalization in ANC utilization and greater convergence across the states. However, a few select states, including Madhya Pradesh and Goa, which had previously had a greater ANC component, showed marginal decline over the study period.

Moving on to institutional deliveries, the southern region was near to attaining $100 \%$ in $2015-$ 16, with progress made in Andhra Pradesh and Karnataka. In the rest of the country there was a phenomenal rise in institutional deliveries during 2006-06 to 2015-2016, particularly in Haryana, Himachal, Chhattisgarh, Bihar and Rajasthan and Uttar Pradesh. This incremental gain in some states was not in keeping with that of other states, particularly in the north-east. Otherwise a high level of regional convergence in institutional deliveries was attained over the study decade. Rising proportion of institutional delivery has implications for the postnatal care of mothers (PNC-M), which has improved substantially over the decade although far from being universal. While almost all states had near to, or more than 50\% uptake of PNC-M in 2015-16, it is rather surprising that this component falls short of uptake levels for institutional deliveries. Therefore, it seems that institutional deliveries do not guarantee PNC-M uptake contributing to the failure of full CoC. The percentage decline in 'no service uptake' over time was near to zero, or in single digits, indicating a rise in uptake of maternal services in general. Although improvements in individual components of care are seen, CoC levels remained poor in 2015-16 and there is therefore a need to examine the pattern of all components of these benchmarks. This was therefore done for ANC and ID, and compliance between them not only improved for these over the study period, but there was a conditionality between the two, i.e. ID conditional to ANC. However, the similar compliance between ANC, ID and PNC-M does not seem to be overtly visible, implying that PNC-M is not strictly conditional on its preceding benchmark of ID over time. 
Table 1. Percentage distribution of uptake of maternal health services in states of India, 2015-16 and 2005-06

\begin{tabular}{|c|c|c|c|c|c|c|c|c|c|c|c|c|c|c|}
\hline \multirow[b]{2}{*}{ Region/state } & \multicolumn{2}{|c|}{ ANC } & \multicolumn{2}{|c|}{ ID } & \multicolumn{2}{|c|}{ PNC-M } & \multicolumn{2}{|c|}{ No service uptake } & \multicolumn{2}{|c|}{ Partial CoC } & \multicolumn{2}{|c|}{ ANC \& ID } & \multicolumn{2}{|c|}{ Full CoC } \\
\hline & $2015-16$ & $2005-06$ & $2015-16$ & 2005-06 & $2015-16$ & $2005-06$ & $2015-16$ & 2005-06 & $2015-16$ & $2005-06$ & $2015-16$ & $2005-06$ & $2015-16$ & 2005-06 \\
\hline \multicolumn{15}{|l|}{ North } \\
\hline Delhi & 89.2 & 88.8 & 87.0 & 63.0 & 65.6 & 58.4 & 3.6 & 7.3 & 39.2 & 44.4 & 80.1 & 60.6 & 57.1 & 48.3 \\
\hline Haryana & 82.3 & 88.3 & 83.5 & 38.8 & 70.8 & 55.8 & 6.8 & 9.6 & 32.3 & 56.3 & 73.8 & 37.8 & 60.8 & 34.0 \\
\hline Himachal Pradesh & 90.4 & 86.4 & 78.2 & 44.0 & 76.4 & 43.1 & 3.3 & 9.5 & 31.1 & 58.7 & 73.7 & 41.2 & 65.4 & 31.9 \\
\hline Jammu \& Kashmir & 90.9 & 84.7 & 87.1 & 53.0 & 76.0 & 48.4 & 3.5 & 12.2 & 25.8 & 45.3 & 81.7 & 51.2 & 70.4 & 42.6 \\
\hline Punjab & 97.1 & 88.9 & 92.1 & 54.8 & 89.3 & 61.9 & 0.6 & 7.1 & 15.6 & 45.9 & 90.0 & 52.9 & 83.8 & 47.0 \\
\hline Rajasthan & 85.5 & 74.9 & 85.8 & 31.8 & 64.9 & 28.8 & 5.0 & 22.3 & 36.3 & 55.4 & 76.6 & 29.5 & 58.6 & 22.2 \\
\hline Uttarakhand & 77.0 & 69.4 & 72.0 & 34.9 & 58.4 & 32.4 & 11.1 & 25.9 & 41.4 & 48.6 & 61.7 & 32.1 & 47.4 & 25.5 \\
\hline \multicolumn{15}{|l|}{ Central } \\
\hline Chhattisgarh & 95.7 & 88.5 & 72.8 & 14.8 & 69.0 & 28.2 & 2.0 & 10.6 & 41.2 & 76.8 & 70.9 & 14.7 & 56.8 & 12.6 \\
\hline Madhya Pradesh & 75.6 & 79.5 & 82.3 & 29.2 & 56.9 & 28.5 & 7.3 & 17.8 & 45.9 & 60.7 & 66.2 & 27.4 & 46.8 & 21.5 \\
\hline Uttar Pradesh & 76.1 & 66.0 & 69.9 & 22.0 & 58.8 & 13.2 & 10.6 & 30.4 & 43.5 & 59.3 & 58.3 & 19.0 & 45.7 & 10.3 \\
\hline \multicolumn{15}{|l|}{ East } \\
\hline Bihar & 55.7 & 34.1 & 66.2 & 21.0 & 45.9 & 15.9 & 17.9 & 55.4 & 53.4 & 35.7 & 42.0 & 13.3 & 28.7 & 9.0 \\
\hline Jharkhand & 76.3 & 58.9 & 64.1 & 19.7 & 48.5 & 16.9 & 12.3 & 38.4 & 51.0 & 49.4 & 54.2 & 17.9 & 36.6 & 12.3 \\
\hline Odisha & 92.9 & 86.9 & 86.6 & 37.9 & 78.5 & 33.3 & 1.8 & 10.5 & 28.9 & 62.9 & 82.1 & 36.3 & 69.1 & 26.6 \\
\hline West Bengal & 90.4 & 91.9 & 77.6 & 44.4 & 63.7 & 40.7 & 3.2 & 6.9 & 42.5 & 61.2 & 71.8 & 43.5 & 54.3 & 32.0 \\
\hline \multicolumn{15}{|l|}{ North-east } \\
\hline Arunachal Pradesh & 56.1 & 52.6 & 55.5 & 32.4 & 30.2 & 22.8 & 25.5 & 41.0 & 53.2 & 42.3 & 37.8 & 26.3 & 21.3 & 16.7 \\
\hline Assam & 87.8 & 70.7 & 73.2 & 24.9 & 57.7 & 14.0 & 6.2 & 27.3 & 43.3 & 60.7 & 67.8 & 23.2 & 50.5 & 12.0 \\
\hline Manipur & 89.5 & 86.3 & 72.8 & 50.1 & 65.9 & 46.4 & 6.5 & 11.9 & 32.5 & 44.4 & 69.1 & 48.6 & 61.0 & 43.7 \\
\hline Meghalaya & 81.1 & 67.6 & 54.8 & 32.3 & 55.7 & 28.8 & 11.7 & 30.2 & 45.3 & 43.9 & 49.4 & 30.9 & 43.1 & 25.8 \\
\hline
\end{tabular}


Table 1. (Continued)

\begin{tabular}{|c|c|c|c|c|c|c|c|c|c|c|c|c|c|c|}
\hline \multirow[b]{2}{*}{ Region/state } & \multicolumn{2}{|c|}{ ANC } & \multicolumn{2}{|c|}{ ID } & \multicolumn{2}{|c|}{ PNC-M } & \multicolumn{2}{|c|}{ No service uptake } & \multicolumn{2}{|c|}{ Partial CoC } & \multicolumn{2}{|c|}{ ANC \& ID } & \multicolumn{2}{|c|}{ Full CoC } \\
\hline & $2015-16$ & $2005-06$ & $2015-16$ & 2005-06 & $2015-16$ & $2005-06$ & $2015-16$ & 2005-06 & $2015-16$ & 2005-06 & $2015-16$ & 2005-06 & $2015-16$ & $2005-06$ \\
\hline Mizoram & 87.9 & 74.3 & 81.7 & 62.3 & 65.8 & 50.4 & 7.5 & 18.4 & 31.1 & 38.1 & 77.5 & 55.2 & 61.3 & 43.6 \\
\hline Nagaland & 45.8 & 57.8 & 35.8 & 13.9 & 23.4 & 10.6 & 43.4 & 40.4 & 39.2 & 50.9 & 25.7 & 12.4 & 17.4 & 8.7 \\
\hline Sikkim & 91.0 & 89.3 & 95.0 & 50.3 & 74.8 & 44.9 & 1.1 & 8.8 & 30.9 & 49.1 & 87.0 & 48.6 & 68.0 & 42.0 \\
\hline Tripura & 88.9 & 78.3 & 82.6 & 50.2 & 63.0 & 30.3 & 4.6 & 17.8 & 36.4 & 57.0 & 76.2 & 47.0 & 58.9 & 25.2 \\
\hline \multicolumn{15}{|l|}{ West } \\
\hline Goa & 96.7 & 97.3 & 98.3 & 93.2 & 92.6 & 75.7 & 0.3 & 1.8 & 10.2 & 24.2 & 95.7 & 92.4 & 89.5 & 74.0 \\
\hline Gujarat & 85.1 & 86.7 & 89.9 & 57.2 & 66.0 & 56.5 & 2.7 & 9.7 & 40.5 & 43.7 & 78.8 & 54.4 & 56.8 & 46.7 \\
\hline Maharashtra & 91.9 & 90.8 & 91.6 & 67.4 & 79.7 & 58.7 & 1.4 & 7.0 & 26.2 & 40.6 & 85.5 & 65.5 & 72.3 & 52.4 \\
\hline \multicolumn{15}{|l|}{ South } \\
\hline Andhra Pradesh & 98.8 & 94.3 & 92.5 & 64.8 & 80.5 & 64.0 & 0.5 & 4.3 & 22.5 & 40.7 & 91.8 & 63.6 & 77.0 & 55.0 \\
\hline Karnataka & 88.0 & 89.3 & 94.6 & 67.3 & 65.8 & 58.3 & 1.7 & 8.0 & 38.3 & 40.5 & 84.5 & 65.3 & 59.9 & 51.6 \\
\hline Kerala & 92.6 & 94.4 & 99.9 & 99.5 & 88.8 & 84.9 & 0.1 & 0.0 & 17.4 & 18.3 & 92.5 & 93.9 & 82.6 & 81.7 \\
\hline Tamil Nadu & 91.4 & 98.6 & 99.2 & 88.5 & 74.2 & 87.1 & 0.3 & 0.2 & 30.0 & 17.9 & 90.8 & 87.7 & 69.8 & 81.9 \\
\hline Telangana & 96.6 & NA & 92.4 & NA & 82.6 & NA & 1.1 & NA & 20.0 & NA & 90.3 & NA & 78.7 & NA \\
\hline$N$ & 155,402 & 29,631 & 148,185 & 17,795 & 119,665 & 16,023 & 14,024 & 5998 & 129,486 & 17,285 & 129,526 & 16,864 & 100941 & 13567 \\
\hline
\end{tabular}

ANC: antenatal care (any visit); ID: institutional delivery; PNC-M: postnatal care for the mother within 2 days of birth; Partial CoC; any one service; Full CoC: all three services. 


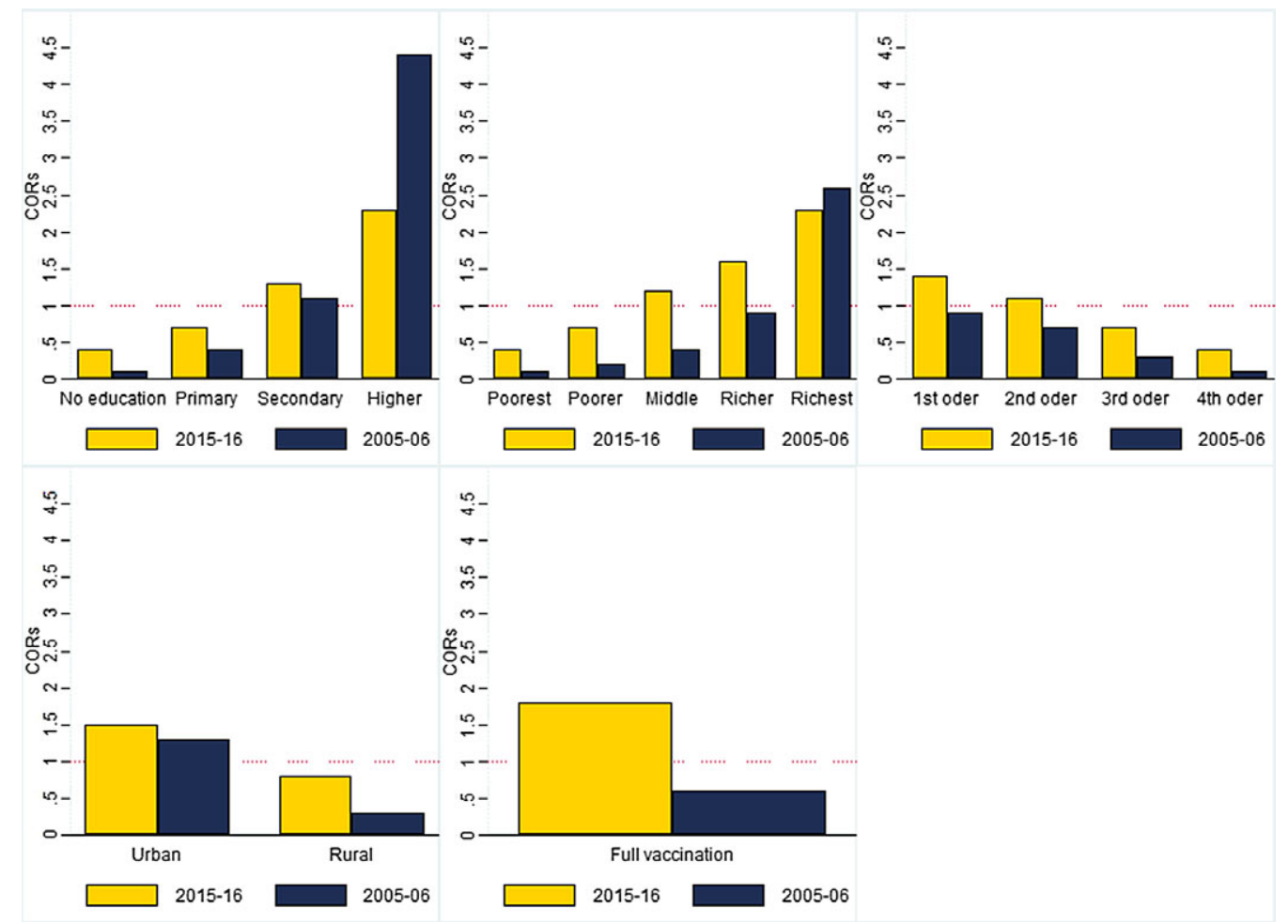

Figure 4. Characteristic odd ratios for continuum of care (CoC) in India, 2005-06 and 2015-16.

\section{Association of $\mathrm{COC}$ with background variables}

Figure 4 shows the CORs for $\mathrm{CoC}$ for $\mathrm{MNCH}$ by urban-rural place of residence, household wealth status (quintile), mother's level of education, birth order and 'full vaccination' levels in 2005-06 and 2015-16. Women residing in urban areas were 1.3 and 1.4 times (10\%), respectively, more likely to achieve full $\mathrm{CoC}$ compared with women in India as a whole. Conversely, women residing in rural areas were 0.1 times (10\%) less likely to achieve full CoC compared with women in India as a whole. Higher household wealth status improved women's chances of achieving full CoC in India over the 10 -year period. The poorest and poor women were $50 \%$ and $10 \%$ less likely to achieve full $\mathrm{CoC}$ compared with 'all women', respectively. However, middle, richer and richest women were $20 \%, 30 \%$ and $40 \%$ more likely, respectively, to achieve full CoC compared with 'all women'. The educational status of the mother influenced achievement of full CoC: as this increased, women were more likely to achieve full CoC. Uneducated and primary educated women were $40 \%$ and $10 \%$ less likely to achieve full CoC compared with 'all women', respectively. However, secondary and higher educated women were $20 \%$ and $40 \%$ more likely to achieve full CoC compared with 'all women'. Birth order also showed improvement in COC in 2015, with 1st birth order being 1.4 times higher compared with total women in 2005, and 1st birth order being 0.9 less likely to have full $\mathrm{CoC}$ compared with the national CoC. Full vaccination of the child has made more progress over the 10-year period, with this being 1.68 times more and 0.68 less likely in 2015-16 and 2005-06 respectively, to have full CoC compared with total women in India. These analyses confirm that mother's educational level and wealth status of the household have positive association with full $\mathrm{CoC}$, but education seems to be stronger compared with wealth. 
While there has been an overall improvement in CoC during the study period, there has been particularly substantial improvement in rural areas leading to a narrowing of rural-urban differentials across the board (Tables 2 and 3). The improvement in $\mathrm{CoC}$ in rural India has been more than two-fold greater than that in urban areas, where improvement was about $10 \%$. The rural improvement in full $\mathrm{CoC}$ was significant in Jharkhand, Assam, Rajasthan, Madhya Pradesh and Chhattisgarh. The improvement in rural areas across all the states was significantly larger than in urban areas. Looking at wealth scores, the improvement seems to have been significant among the poorest and poor categories, although improvement was experienced across all wealth classes. There is a differential in the regional pattern of improvement in full $\mathrm{CoC}$ across wealth score categories in the sense that it is differentially responsive to economic status across the states.

Such association is made with the distribution of full continuum of care $(\mathrm{CoC})$ by place of residence, household wealth, mother's education level and birth order in India and its states. Nationally, the proportion of women reporting full CoC increased from 55.7\% in 2005-06 to $66.3 \%$ in $2015-16$ in urban areas, and from $21.3 \%$ to $50.9 \%$ in rural areas However, in the most recent round of the NFHS, full $\mathrm{CoC}$ was higher in rural areas in twelve states. This pattern was noted mainly in the southern and north-eastern states. There were mixed patterns in states within other regions. In Kerala, for example, the percentage of women who had full CoC in rural areas was $79 \%$, compared with $80 \%$ in urban areas. In India, based on the household status spike from poorest to richest, full coverage of $\mathrm{CoC}$ in 2005-06 and 2015-16 among the richest increased from $70 \%$ to $75 \%$, and among the poorest increased from $7.5 \%$ to $32 \%$. Thus, there is a significant association between household wealth status and full $\mathrm{CoC}$ nationally. However, among states, the association between household wealth and full $\mathrm{CoC}$ is stronger in the northern and north-eastern states compared with the southern states. However, the percentage of poorest mothers who received full $\mathrm{CoC}$ in northern and north-eastern states was much lower than in the southern states. Furthermore, the difference in the percentage of women having full $\mathrm{CoC}$ between poorer and richest mothers is less in southern Indian states compared with the rest of the country. For example, in Kerala, a southern state, the percentage of mothers who had full CoC among the poorest increased from $63 \%$ to $71 \%$, but fell for the richest from $84 \%$ to $83 \%$.

In India, coverage of full $\mathrm{CoC}$ for $\mathrm{MNCH}$ services among higher educated mothers fell from $80.5 \%$ to $75.1 \%$, compared with an increase from $11.7 \%$ to $35.9 \%$ among uneducated mothers over the study period. Thus, for those with higher education $\mathrm{CoC}$ has declined and for uneducated women $\mathrm{CoC}$ has improved. Among primary educated mothers, coverage of full CoC was $24.3 \%$, and for secondary educated mothers coverage increased from $27 \%$ to $48.9 \%$. This clearly shows that, generally, education and full $\mathrm{CoC}$ are positively related in India. This pattern is generally true for all the states. However, there is a smaller difference in the percentage of women having full $\mathrm{CoC}$ between the higher educated women and uneducated women in the southern and western states compared with the states in other regions.

Table 4 shows the percentage distribution of full maternal $\mathrm{CoC}$ and child full vaccination at 12-23 months. Nationally, the percentages of maternal uptake of full $\mathrm{CoC}$ and child full vaccination were $44.8 \%$ and $62.1 \%$ in $2005-06$ and $2015-16$, respectively. It is clear that full maternal CoC improves child full vaccination. However, among the states, full $\mathrm{CoC}$ of mother and child full vaccination were more evident. In the west, Goa's achievements of full CoC for mother and child full vaccination were $73.6 \%$ and $100 \%$ in $2005-06$ and $2015-16$, respectively, whereas the central states of Chhattisgarh and Uttar Pradesh showed tremendous improvement - from $24.7 \%$ to $61.3 \%$ and $22.4 \%$ to $56.7 \%$, respectively. In the eastern state of Bihar, the percentage of CoC was $13.5 \%$ and $35.1 \%$ in $2005-06$ and $2015-16$, respectively, and in the north-eastern state of Assam the corresponding figures were $17.7 \%$ and $61.6 \%$. 
Table 2. Full continuum of care (\%) by mother's place of residence and household wealth status by states of India, 2005-06 and 2015-16

\begin{tabular}{|c|c|c|c|c|c|c|c|c|c|c|c|c|c|c|}
\hline & \multicolumn{4}{|c|}{ Place of residence } & \multicolumn{10}{|c|}{ Wealth status } \\
\hline & \multicolumn{2}{|c|}{ Urban } & \multicolumn{2}{|c|}{ Rural } & \multicolumn{2}{|c|}{ Poorest } & \multicolumn{2}{|c|}{ Poorer } & \multicolumn{2}{|c|}{ Middle } & \multicolumn{2}{|c|}{ Richer } & \multicolumn{2}{|c|}{ Richest } \\
\hline & $2015-16$ & $2005-06$ & $2015-16$ & $2005-06$ & $2015-16$ & $2005-06$ & $2015-16$ & 2005-06 & $2015-16$ & $2005-06$ & $2015-16$ & $2005-06$ & 2015-16 & $2005-06$ \\
\hline All India & 66.3 & 55.7 & 50.9 & 21.3 & 32.4 & 7.5 & 49.0 & 15.3 & 60.9 & 28.6 & 68.3 & 45.3 & 75.1 & 70.5 \\
\hline \multicolumn{15}{|l|}{ North } \\
\hline Delhi & 57.1 & 49.1 & 76.0 & 39.4 & 0.0 & 33.3 & 23.2 & 13.7 & 49.3 & 16.7 & 51.1 & 23.0 & 64.5 & 65.0 \\
\hline Haryana & 59.4 & 58.9 & 61.7 & 24.8 & 16.1 & 6.7 & 34.6 & 7.8 & 53.3 & 20.1 & 59.6 & 30.7 & 71.6 & 64.1 \\
\hline Himachal Pradesh & 83.0 & 45.7 & 64.0 & 30.3 & 29.9 & 13.7 & 35.3 & 11.9 & 52.7 & 19.3 & 68.6 & 29.2 & 81.3 & 48.4 \\
\hline Jammu \& Kashmir & 82.8 & 66.4 & 66.7 & 35.9 & 40.4 & 17.3 & 60.9 & 17.5 & 72.9 & 32.1 & 77.9 & 49.3 & 82.5 & 71.3 \\
\hline Punjab & 83.3 & 57.0 & 84.1 & 41.0 & 54.2 & 6.6 & 65.8 & 8.2 & 74.9 & 27.3 & 78.4 & 36.0 & 88.9 & 67.9 \\
\hline Rajasthan & 67.7 & 50.3 & 56.0 & 14.3 & 44.0 & 8.8 & 53.2 & 10.6 & 58.2 & 16.4 & 65.9 & 30.2 & 74.5 & 58.3 \\
\hline Uttarakhand & 59.1 & 48.9 & 41.6 & 17.8 & 20.4 & 3.1 & 29.0 & 4.4 & 37.5 & 9.7 & 50.9 & 21.2 & 70.4 & 58.5 \\
\hline \multicolumn{15}{|l|}{ Central } \\
\hline Chhattisgarh & 70.1 & 51.8 & 53.1 & 4.1 & 41.7 & 2.3 & 56.3 & 3.0 & 60.0 & 11.3 & 65.4 & 36.1 & 81.2 & 83.5 \\
\hline Madhya Pradesh & 60.0 & 46.9 & 41.8 & 13.4 & 29.7 & 6.3 & 44.6 & 15.5 & 53.8 & 27.5 & 60.1 & 39.8 & 68.4 & 68.8 \\
\hline Uttar Pradesh & 56.1 & 26.3 & 43.0 & 6.1 & 30.2 & 1.7 & 42.0 & 4.9 & 49.2 & 6.3 & 57.8 & 15.1 & 72.8 & 45.0 \\
\hline \multicolumn{15}{|l|}{ East } \\
\hline Bihar & 41.1 & 25.9 & 27.2 & 6.7 & 21.2 & 3.1 & 31.2 & 4.4 & 39.9 & 8.4 & 50.4 & 13.1 & 65.4 & 57.3 \\
\hline Jharkhand & 54.0 & 41.0 & 32.3 & 5.3 & 23.2 & 2.5 & 41.3 & 5.1 & 48.2 & 17.8 & 60.1 & 27.2 & 69.5 & 72.8 \\
\hline Odisha & 70.7 & 46.3 & 69.1 & 23.1 & 58.9 & 10.3 & 71.2 & 20.1 & 76.9 & 35.3 & 79.7 & 51.6 & 83.1 & 71.6 \\
\hline West Bengal & 61.9 & 63.3 & 51.3 & 22.9 & 38.7 & 12.4 & 50.2 & 19.9 & 61.3 & 35.2 & 68.6 & 56.0 & 76.6 & 87.8 \\
\hline \multicolumn{15}{|l|}{ North-east } \\
\hline Arunachal Pradesh & 24.8 & 31.1 & 20.3 & 11.5 & 7.5 & 3.0 & 19.3 & 5.6 & 27.4 & 13.4 & 29.6 & 27.8 & 26.7 & 55.0 \\
\hline Assam & 67.7 & 32.5 & 48.4 & 9.0 & 33.3 & 1.7 & 48.5 & 6.4 & 63.8 & 14.0 & 70.6 & 24.7 & 78.6 & 45.0 \\
\hline
\end{tabular}


Table 2. (Continued)

\begin{tabular}{|c|c|c|c|c|c|c|c|c|c|c|c|c|c|c|}
\hline & \multicolumn{4}{|c|}{ Place of residence } & \multicolumn{10}{|c|}{ Wealth status } \\
\hline & \multicolumn{2}{|c|}{ Urban } & \multicolumn{2}{|c|}{ Rural } & \multicolumn{2}{|c|}{ Poorest } & \multicolumn{2}{|c|}{ Poorer } & \multicolumn{2}{|c|}{ Middle } & \multicolumn{2}{|c|}{ Richer } & \multicolumn{2}{|c|}{ Richest } \\
\hline & 2015-16 & 2005-06 & 2015-16 & 2005-06 & 2015-16 & 2005-06 & 2015-16 & 2005-06 & 2015-16 & 2005-06 & 2015-16 & 2005-06 & 2015-16 & 2005-06 \\
\hline Manipur & 73.4 & 62.9 & 54.2 & 35.5 & 24.8 & 4.9 & 47.7 & 17.2 & 68.4 & 31.4 & 76.3 & 61.3 & 82.1 & 82.6 \\
\hline Meghalaya & 71.7 & 66.5 & 38.2 & 17.1 & 22.1 & 2.5 & 31.7 & 4.7 & 54.2 & 22.3 & 73.4 & 55.2 & 77.4 & 75.7 \\
\hline Mizoram & 74.1 & 65.8 & 46.7 & 23.3 & 14.1 & 4.4 & 32.5 & 5.8 & 57.6 & 20.5 & 69.9 & 52.0 & 79.1 & 66.3 \\
\hline Nagaland & 28.8 & 24.4 & 12.7 & 4.0 & 2.9 & 0.8 & 8.9 & 1.5 & 20.8 & 4.7 & 33.2 & 13.9 & 46.5 & 39.4 \\
\hline Sikkim & 73.9 & 78.7 & 65.1 & 34.7 & 67.6 & 11.1 & 55.3 & 17.0 & 69.0 & 20.6 & 69.0 & 41.3 & 72.4 & 78.9 \\
\hline Tripura & 69.4 & 32.5 & 55.3 & 23.8 & 36.7 & 1.3 & 55.1 & 19.0 & 69.9 & 27.0 & 72.6 & 41.7 & 74.5 & 56.7 \\
\hline \multicolumn{15}{|l|}{ West } \\
\hline Goa & 89.8 & 75.2 & 88.9 & 72.5 & 0.0 & 50.7 & 78.4 & 58.2 & 88.3 & 74.7 & 88.8 & 73.1 & 92.2 & 76.8 \\
\hline Gujarat & 62.5 & 65.5 & 52.5 & 34.4 & 39.9 & 16.0 & 46.1 & 26.0 & 55.7 & 26.2 & 62.5 & 54.7 & 65.8 & 76.3 \\
\hline Maharashtra & 76.8 & 66.9 & 68.8 & 39.5 & 50.8 & 12.5 & 61.7 & 27.2 & 73.6 & 43.9 & 78.1 & 59.7 & 80.8 & 77.6 \\
\hline \multicolumn{15}{|l|}{ South } \\
\hline Andhra Pradesh & 83.3 & 70.8 & 74.6 & 47.4 & 62.5 & 27.5 & 70.1 & 42.7 & 76.6 & 48.3 & 80.3 & 70.0 & 83.9 & 83.9 \\
\hline Karnataka & 62.1 & 66.0 & 58.4 & 42.4 & 49.6 & 17.7 & 53.6 & 30.3 & 59.8 & 48.3 & 63.0 & 65.7 & 65.3 & 82.6 \\
\hline Kerala & 80.2 & 86.1 & 84.7 & 79.6 & 71.2 & 63.6 & 86.9 & 61.3 & 78.5 & 77.9 & 83.1 & 82.5 & 83.1 & 84.0 \\
\hline Tamil Nadu & 70.0 & 88.7 & 69.5 & 76.2 & 62.4 & 54.5 & 69.5 & 74.2 & 67.4 & 78.2 & 71.3 & 91.9 & 71.8 & 96.4 \\
\hline Telangana & 82.7 & $\mathrm{NA}$ & 75.3 & $\mathrm{NA}$ & 57.3 & $\mathrm{NA}$ & 68.6 & $\mathrm{NA}$ & 82.6 & $\mathrm{NA}$ & 85.4 & $\mathrm{NA}$ & 79.7 & $\mathrm{NA}$ \\
\hline$N$ & 47,833 & 14,527 & 143,065 & 22,323 & 46,782 & 6154 & 43,739 & 6468 & 38,393 & 7418 & 33,212 & 8136 & 28,772 & 8674 \\
\hline
\end{tabular}


Table 3. Full continuum of care (\%) by mother's education level and birth order by states of India, 2005-06 and 2015-16

\begin{tabular}{|c|c|c|c|c|c|c|c|c|c|c|c|c|c|c|c|c|}
\hline & \multicolumn{8}{|c|}{ Mother's education level } & \multicolumn{8}{|c|}{ Birth order } \\
\hline & \multicolumn{2}{|c|}{ No education } & \multicolumn{2}{|c|}{ Primary } & \multicolumn{2}{|c|}{ Secondary } & \multicolumn{2}{|c|}{ Higher } & \multicolumn{2}{|c|}{1 st } & \multicolumn{2}{|c|}{ 2nd } & \multicolumn{2}{|c|}{$3 r d$} & \multicolumn{2}{|c|}{$\geq 4$ th } \\
\hline & $\begin{array}{c}2015- \\
16\end{array}$ & $\begin{array}{c}2005- \\
06\end{array}$ & $\begin{array}{c}2015- \\
16\end{array}$ & $\begin{array}{c}2005- \\
06\end{array}$ & $\begin{array}{c}2015- \\
16\end{array}$ & $\begin{array}{c}2005- \\
06\end{array}$ & $\begin{array}{c}2015- \\
16\end{array}$ & $\begin{array}{c}2005- \\
06\end{array}$ & $\begin{array}{c}2015- \\
16\end{array}$ & $\begin{array}{c}2005- \\
06\end{array}$ & $\begin{array}{c}2015- \\
16\end{array}$ & $\begin{array}{c}2005- \\
06\end{array}$ & $\begin{array}{c}2015- \\
16\end{array}$ & $\begin{array}{c}2005- \\
06\end{array}$ & $\begin{array}{c}2015- \\
16\end{array}$ & $\begin{array}{c}2005- \\
06\end{array}$ \\
\hline All India & 35.9 & 11.7 & 48.9 & 27.0 & 63.9 & 50.2 & 75.1 & 80.5 & 65.6 & 45.7 & 59.5 & 40.0 & 47.6 & 23.3 & 33.1 & 10.8 \\
\hline \multicolumn{17}{|l|}{ North } \\
\hline Delhi & 48.7 & 22.0 & 50.4 & 14.3 & 56.5 & 53.7 & 70.6 & 81.5 & 63.6 & 58.2 & 61.5 & 57.8 & 43.4 & 39.3 & 44.4 & 19.2 \\
\hline Haryana & 40.9 & 12.4 & 52.9 & 22.3 & 66.2 & 47.9 & 75.4 & 74.6 & 69.7 & 52.7 & 61.9 & 36.0 & 55.8 & 28.8 & 38.8 & 12.9 \\
\hline Himachal Pradesh & 36.5 & 9.6 & 28.8 & 12.3 & 65.1 & 34.9 & 84.1 & 70.6 & 74.8 & 43.8 & 64.9 & 34.0 & 51.2 & 18.3 & 39.2 & 15.7 \\
\hline Jammu \& Kashmir & 60.0 & 28.2 & 72.4 & 37.5 & 74.8 & 57.2 & 82.4 & 91.4 & 76.9 & 60.8 & 74.0 & 50.8 & 67.8 & 34.1 & 52.3 & 25.0 \\
\hline Punjab & 72.9 & 22.9 & 75.1 & 32.3 & 85.7 & 57.8 & 90.9 & 95.0 & 88.4 & 61.4 & 82.3 & 48.8 & 81.0 & 35.3 & 67.0 & 20.9 \\
\hline Rajasthan & 47.7 & 12.7 & 59.7 & 25.1 & 65.8 & 45.3 & 76.1 & 83.7 & 68.1 & 34.7 & 61.3 & 27.6 & 54.1 & 17.8 & 42.7 & 12.9 \\
\hline Uttarakhand & 25.4 & 6.6 & 34.4 & 12.7 & 49.8 & 32.4 & 73.6 & 77.8 & 61.8 & 40.2 & 49.3 & 34.2 & 35.6 & 16.6 & 27.2 & 7.8 \\
\hline \multicolumn{17}{|l|}{ Central } \\
\hline Chhattisgarh & 41.7 & 2.8 & 50.5 & 8.1 & 61.5 & 23.8 & 84.2 & 86.9 & 66.8 & 23.3 & 58.4 & 16.1 & 48.6 & 5.8 & 41.4 & 5.9 \\
\hline Madhya Pradesh & 34.4 & 10.7 & 43.4 & 22.6 & 53.5 & 37.0 & 70.1 & 79.2 & 55.9 & 34.9 & 48.4 & 30.4 & 42.2 & 12.9 & 32.5 & 11.5 \\
\hline Uttar Pradesh & 33.3 & 4.3 & 42.6 & 8.5 & 54.1 & 19.2 & 70.8 & 58.4 & 59.3 & 19.9 & 50.2 & 15.7 & 41.9 & 8.3 & 32.0 & 4.5 \\
\hline \multicolumn{17}{|l|}{ East } \\
\hline Bihar & 20.6 & 4.0 & 28.4 & 8.2 & 39.2 & 22.0 & 62.9 & 55.2 & 38.5 & 16.0 & 31.5 & 12.3 & 27.1 & 6.8 & 19.4 & 4.4 \\
\hline Jharkhand & 22.9 & 3.6 & 32.4 & 6.6 & 45.6 & 33.6 & 65.2 & 75.9 & 47.0 & 23.5 & 38.6 & 17.2 & 30.9 & 8.8 & 23.4 & 3.7 \\
\hline Odisha & 53.7 & 8.2 & 68.7 & 30.0 & 76.1 & 42.7 & 79.9 & 88.3 & 77.0 & 43.6 & 71.0 & 29.0 & 60.9 & 14.3 & 47.2 & 10.1 \\
\hline West Bengal & 35.5 & 15.2 & 46.0 & 24.5 & 59.9 & 51.0 & 77.5 & 86.7 & 64.5 & 48.5 & 52.9 & 34.3 & 37.2 & 20.4 & 23.1 & 7.8 \\
\hline \multicolumn{17}{|l|}{ North-east } \\
\hline $\begin{array}{l}\text { Arunachal } \\
\text { Pradesh }\end{array}$ & 9.0 & 7.5 & 19.6 & 14.1 & 29.7 & 31.7 & 26.5 & 46.4 & 29.9 & 29.7 & 24.3 & 17.8 & 17.7 & 19.0 & 8.8 & 7.4 \\
\hline Assam & 33.9 & 3.0 & 41.3 & 7.7 & 57.5 & 19.6 & 73.9 & 47.2 & 61.7 & 22.7 & 52.5 & 12.3 & 39.2 & 6.4 & 27.7 & 2.5 \\
\hline
\end{tabular}


Table 3. (Continued)

\begin{tabular}{|c|c|c|c|c|c|c|c|c|c|c|c|c|c|c|c|c|}
\hline & \multicolumn{8}{|c|}{ Mother's education level } & \multicolumn{8}{|c|}{ Birth order } \\
\hline & \multicolumn{2}{|c|}{ No education } & \multicolumn{2}{|c|}{ Primary } & \multicolumn{2}{|c|}{ Secondary } & \multicolumn{2}{|c|}{ Higher } & \multicolumn{2}{|c|}{1 st } & \multicolumn{2}{|c|}{ 2nd } & \multicolumn{2}{|c|}{$3 r d$} & \multicolumn{2}{|c|}{$\geq 4$ th } \\
\hline & $\begin{array}{c}2015- \\
16\end{array}$ & $\begin{array}{c}2005- \\
06\end{array}$ & $\begin{array}{c}2015- \\
16\end{array}$ & $\begin{array}{c}2005- \\
06\end{array}$ & $\begin{array}{c}2015- \\
16\end{array}$ & $\begin{array}{c}2005- \\
06\end{array}$ & $\begin{array}{c}2015- \\
16\end{array}$ & $\begin{array}{c}2005- \\
06\end{array}$ & $\begin{array}{c}2015- \\
16\end{array}$ & $\begin{array}{c}2005- \\
06\end{array}$ & $\begin{array}{c}2015- \\
16\end{array}$ & $\begin{array}{c}2005- \\
06\end{array}$ & $\begin{array}{c}2015- \\
16\end{array}$ & $\begin{array}{c}2005- \\
06\end{array}$ & $\begin{array}{c}2015- \\
16\end{array}$ & $\begin{array}{c}2005- \\
06\end{array}$ \\
\hline Manipur & 37.7 & 19.3 & 36.7 & 25.3 & 64.7 & 50.9 & 79.1 & 78.7 & 72.0 & 62.1 & 64.7 & 48.2 & 54.7 & 37.0 & 35.3 & 23.4 \\
\hline Meghalaya & 22.9 & 13.7 & 36.2 & 18.3 & 50.8 & 39.0 & 74.8 & 82.1 & 54.1 & 33.2 & 46.4 & 32.4 & 39.8 & 20.7 & 33.8 & 21.3 \\
\hline Mizoram & 8.4 & 3.8 & 42.2 & 28.5 & 69.8 & 50.6 & 70.4 & 75.5 & 72.0 & 50.0 & 61.6 & 48.1 & 60.8 & 46.6 & 49.3 & 29.4 \\
\hline Nagaland & 6.5 & 2.4 & 10.0 & 2.3 & 20.0 & 12.9 & 43.8 & 43.1 & 26.6 & 18.5 & 21.3 & 13.7 & 16.8 & 6.4 & 6.6 & 3.3 \\
\hline Sikkim & 63.7 & 16.5 & 66.4 & 32.5 & 68.8 & 59.8 & 71.8 & 89.1 & 73.5 & 56.8 & 67.0 & 46.2 & 54.6 & 31.9 & 50.5 & 14.9 \\
\hline Tripura & 39.2 & 7.1 & 45.5 & 12.7 & 64.8 & 39.5 & 69.9 & 61.0 & 66.6 & 39.6 & 57.3 & 22.5 & 38.0 & 9.0 & 18.3 & 3.5 \\
\hline \multicolumn{17}{|l|}{ West } \\
\hline Goa & 85.4 & 54.1 & 86.8 & 70.2 & 88.7 & 76.6 & 94.4 & 82.0 & 93.2 & 74.3 & 87.5 & 74.9 & 85.4 & 79.2 & 82.8 & 59.8 \\
\hline Gujarat & 42.8 & 25.8 & 51.8 & 37.3 & 61.2 & 61.7 & 68.0 & 85.8 & 64.6 & 59.6 & 56.5 & 57.9 & 50.1 & 35.5 & 42.1 & 23.5 \\
\hline Maharashtra & 47.0 & 23.1 & 61.7 & 32.6 & 76.0 & 61.9 & 80.7 & 85.9 & 77.8 & 63.1 & 73.1 & 56.8 & 66.3 & 42.1 & 55.8 & 29.3 \\
\hline \multicolumn{17}{|l|}{ South } \\
\hline Andhra Pradesh & 65.8 & 35.6 & 73.4 & 55.0 & 80.8 & 73.4 & 84.6 & 90.3 & 81.3 & 65.7 & 77.7 & 57.0 & 71.1 & 44.5 & 52.5 & 33.5 \\
\hline Karnataka & 42.7 & 23.0 & 48.7 & 50.4 & 64.2 & 65.0 & 69.0 & 84.5 & 65.2 & 65.4 & 59.5 & 56.5 & 54.2 & 37.9 & 42.7 & 26.4 \\
\hline Kerala & 55.1 & 61.5 & 76.0 & 65.2 & 82.6 & 80.6 & 82.9 & 89.7 & 81.6 & 81.9 & 83.6 & 83.2 & 81.7 & 79.6 & 85.4 & 75.6 \\
\hline Tamil Nadu & 64.1 & 68.9 & 64.5 & 73.6 & 70.5 & 85.9 & 70.5 & 97.2 & 70.1 & 89.1 & 71.2 & 83.8 & 63.6 & 71.9 & 65.3 & 65.2 \\
\hline Telangana & 62.4 & NA & 71.1 & NA & 83.8 & NA & 86.0 & NA & 83.9 & NA & 78.7 & NA & 74.1 & NA & 56.8 & NA \\
\hline$N$ & 55,165 & 14,094 & 26,712 & 5251 & 88,871 & 14,215 & 20,150 & 3289 & 61,807 & 10,394 & 62,484 & 10,934 & 33,064 & 6297 & 33,543 & 9225 \\
\hline
\end{tabular}




\section{Impact of level of a service on the next service to achieve complete continuum of care}

Table 5 shows changes in each component of CoC during 2005-06 to 2015-16. It also shows how each component was conditional to its preceding component. The percentage of mothers who had ID with ANC increased from $50.9 \%$ to $87.6 \%$ over the study decade, whereas the percentage having ID with PNC-M declined from $76.8 \%$ to $74.7 \%$. Although compliance with ID was reasonably high with PNC-M, its share was relatively lower without PNC-M. Similarly, the response of compliance with child full vaccination was verified against compliance with ID, and there was an improvement in ID with child full vaccination from $61.31 \%$ to $65.6 \%$ over time. Compliance with ID was undoubtedly higher among those complying with child full vaccination.

The findings presented in Table 6 indicate that the odds of ID conditioned by the three components decreased over time at the national level. For instance, in 2005-06 the odds of ID with ANC were 9.0 (CI 8.4-9.7) times higher, compared with 4.5 (CI 4.4-4.6) times higher in 2015-16. A similar pattern was observed for PNC-M. Those who had ID had a higher chance of taking PNC-M in 2005-06 (33.8; CI; 31.9-35.9) compared with 2015-16 (11.2; CI 10.9-11.5). Also, mothers who had ID had higher odds of child full vaccination in 2005-06 (3.6; CI 3.3-4.0) compared with 2015-16 (2.3; CI 2.2-2.4).

Therefore, the analysis shows an improvement in $\mathrm{CoC}$ over the 10-year period, but the implementation of JSY did not appear to ensure maternal and child health improvement. After the implementation of NRHM in 2005 all over India, with the condition of institutional delivery, the likelihood of having PNC-M and child full vaccination declined. However, the fact remains that the odds of ID are undoubtedly positively conditioned by other components of CoC. Verification of this pattern across the states presents a mixed picture. Furthermore, the variation in the odds of ID in response to compliance with other components of $\mathrm{CoC}$ is also influenced by the extent of rising compliance in such components over time. The conditional analysis reveals the extent to which qualifying a specific benchmark in the continuum is conditioned by the qualification of the prior benchmark. Such a depiction can guide the prioritization and emphasis on specific benchmarks that would ensure continuum for the rest of the benchmarks.

\section{Discussion}

Increasing the coverage of continuum of care $(\mathrm{CoC})$ for maternal and child health has been shown to be a pre-requisite to ensuring all women and children receive the health care necessary to reduce maternal, newborn and child mortality and morbidity (Bryce et al., 2013). Increasing $\mathrm{CoC}$ for maternal, neonatal and child health $(\mathrm{MNCH})$ is key to achieving SDG-3 - mainly reducing the maternal mortality ratio below 70 per 100,000 live births by 2030 . This study revealed that in India between 2005-06 and 2015-16 there was an increase of 30.5\% and 55.5\% of women attaining full $\mathrm{CoC}$ with compliance with the three key $\mathrm{MNCH}$ indicators $\mathrm{ANC}$, institutional delivery and postnatal care of the mother. At the same period, there was a reduction, from $20.1 \%$ to $6.3 \%$, in the proportion of women not complying with any of the three $\mathrm{MNCH}$ services, and a reduction of $49.4 \%$ to $38.18 \%$ in those receiving at least one of the three $\mathrm{MNCH}$ services. Significant variations in the level of $\mathrm{CoC}$ were noted across states and socioeconomic groups. Overall, socially and economically more advanced states had higher coverage of full CoC than economically less advanced states; broadly, the southern states of Kerala and Tamil Nadu had higher coverage of $\mathrm{CoC}$ than other states, particularly those in the north-east. More efficient health systems, greater knowledge about health services and favourable attitudes towards the need for maternal and child health services in the southern states may have contributed to these interstate variations (Navaneetham \& Dharmalingam, 2002). Although the Government of India launched one of the largest conditional cash transfer programmes in the world, the Janani Suraksha Yojana (JSY), in 2005 to reduce maternal and neonatal mortality among the poor, it appears that the programme has had a different impact on maternal and child health service 
Table 4. Percentage distribution of full continuum of care and no service uptake with child full vaccination in India and states, 2005-06 and 2015-16

\begin{tabular}{|c|c|c|c|c|}
\hline & \multicolumn{2}{|c|}{$\begin{array}{l}\text { No service uptake+Full } \\
\text { vaccination }\end{array}$} & \multicolumn{2}{|c|}{ Full $\mathrm{CoC}+$ Full vaccination } \\
\hline & 2005-06 & $2015-16$ & $2005-06$ & 2015-16 \\
\hline All India & 7.4 & 3.1 & 44.8 & 62.1 \\
\hline \multicolumn{5}{|l|}{ North } \\
\hline Delhi & 5.3 & 0.5 & 47.5 & 70.0 \\
\hline Haryana & 1.4 & 2.1 & 41.9 & 71.0 \\
\hline Himachal Pradesh & 4.9 & 1.2 & 34.7 & 71.3 \\
\hline Jammu \& Kashmir & 5.3 & 1.4 & 56.5 & 78.4 \\
\hline Punjab & 5.4 & 0.0 & 55.7 & 86.9 \\
\hline Rajasthan & 2.4 & 0.9 & 39.9 & 70.2 \\
\hline Uttarakhand & 15.1 & 6.6 & 37.9 & 52.8 \\
\hline \multicolumn{5}{|l|}{ Central } \\
\hline Chhattisgarh & 7.6 & 1.0 & 24.7 & 61.3 \\
\hline Madhya Pradesh & 5.4 & 3.1 & 35.5 & 55.3 \\
\hline Uttar Pradesh & 9.2 & 4.4 & 22.4 & 56.7 \\
\hline \multicolumn{5}{|l|}{ East } \\
\hline Bihar & 42.7 & 11.3 & 13.5 & 35.1 \\
\hline Jharkhand & 15.0 & 8.5 & 23.1 & 40.5 \\
\hline Odisha & 6.3 & 0.8 & 36.2 & 71.7 \\
\hline West Bengal & 1.5 & 2.9 & 33.3 & 57.4 \\
\hline \multicolumn{5}{|l|}{ North-east } \\
\hline Arunachal Pradesh & 16.0 & 5.9 & 19.0 & 36.9 \\
\hline Assam & 12.4 & 0.7 & 17.7 & 61.6 \\
\hline Manipur & 3.5 & 2.0 & 65.2 & 71.4 \\
\hline Meghalaya & 17.3 & 5.7 & 25.3 & 47.7 \\
\hline Mizoram & 9.0 & 3.4 & 52.2 & 62.4 \\
\hline Nagaland & 15.6 & 21.9 & 17.0 & 29.7 \\
\hline Sikkim & 2.9 & 0.0 & 44.2 & 73.0 \\
\hline Tripura & 3.8 & 2.9 & 36.1 & 65.9 \\
\hline \multicolumn{5}{|l|}{ West } \\
\hline Goa & 0.6 & 0.0 & 73.6 & 100.0 \\
\hline Gujarat & 3.9 & 1.0 & 56.8 & 63.1 \\
\hline Maharashtra & 1.8 & 0.7 & 57.5 & 75.2 \\
\hline \multicolumn{5}{|l|}{ South } \\
\hline Andhra Pradesh & 0.0 & 0.0 & 70.0 & 75.7 \\
\hline Karnataka & 3.1 & 0.1 & 60.1 & 63.3 \\
\hline
\end{tabular}


Table 4. (Continued)

\begin{tabular}{|c|c|c|c|c|}
\hline & \multicolumn{2}{|c|}{$\begin{array}{l}\text { No service uptake+Full } \\
\text { vaccination }\end{array}$} & \multicolumn{2}{|c|}{ Full $\mathrm{CoC}+$ Full vaccination } \\
\hline & 2005-06 & 2015-16 & 2005-06 & $2015-16$ \\
\hline Kerala & 0.0 & 0.0 & 88.5 & 85.0 \\
\hline Tamil Nadu & 0.0 & 0.0 & 84.3 & 73.6 \\
\hline Telangana & NA & 0.0 & NA & 85.5 \\
\hline$N$ & 239 & 978 & 2239 & 17,255 \\
\hline
\end{tabular}

indicators across the regions and states of India. It is important to understand bottlenecks in service delivery in each state in terms of accessibility, acceptability, contact and effectiveness of coverage (Tanahashi, 1978).

This study revealed a positive association between household wealth status and women achieving full CoC for MNCH. Previous studies have also reported that wealth status is a determinant of health care utilization in India (Pallikadavath et al., 2004; Kerber et al., 2007; Titaley et al., 2009; Guliani et al., 2012; Johar et al., 2018; Mothupi et al., 2018). It seems that the ability of JSY to increase demand for maternal health care services among poor women by mitigating economic barriers is limited. The rural-urban and educational inequalities in uptake of MNCH services observed in this study is a concern as the JSY focuses on poor, disadvantaged social groups such as Scheduled Castes and Tribes, and low performing states. Generally, the poor and less-educated women in most regions in India have a significantly low uptake of full CoC. It appears that incentive mechanisms and recruitment of poor pregnant women into the JSY programme may not be effective. There is therefore a need to focus on poor and less-educated women when ASHA recruit village women into the JSY programme.

The role of ANC in increasing the chances of institutional delivery was confirmed in this study. Almost all women in the study who had institutional deliveries had availed ANC, with is a strong positive association between ANC and institutional delivery. Previous studies have found that women's exposure to ANC determines further use of services in the continuum of care (WHO, 2016; Mohammad \& Pallikadavath, 2018). Generally, uptake of ANC depends on women's perception about the services and experience she, or others in her family, have had with the health system (Bloom et al., 1999; Magadi et al., 2003; Bhutta et al., 2010). Given the effect of ANC on institutional delivery, it is important to increase ANC coverage in Indian states where it is currently low. Some of the eastern and north-eastern states have particularly low ANC and they require special attention. As ASHA are the primary contact between pregnant women and the health system, this contact needs to be improved to increase ANC coverage. There is a need to explore how the current payment mechanism of JSY linked to institutional delivery can be extended to ANC in states where ANC uptake is low. It may be noted here that JSY provides cash incentives to both women and ASHA workers for institutional deliveries irrespective of whether or not the women had availed ANC or other MNCH services in the continuum. The primary payment criterion has been institutional delivery (MoHFW 2018b). State-specific amendments to the JSY could be explored to increase ANC utilization in states where ANC coverage is low.

Institutional delivery is a precursor for postnatal care uptake by mothers. This study confirms that women who have had an institutional delivery have a higher likelihood of having postnatal care compared with women who did not have an institutional delivery. It is therefore important that the JSY programme continues its financial support of poor women for institutional delivery. Institutional delivery is particularly low in some of the north-eastern states. This is of particular concern given its effect on the uptake of postnatal care by mothers. The low conditional odds of postnatal care for mothers in these states indicate that women who do not deliver at health 
Table 5. Institutional delivery (ID) conditional percentage distribution of ANC, postnatal care for mother (PNC-M) and child full vaccination, 2005-06 and 2015-16

\begin{tabular}{|c|c|c|c|c|c|c|c|c|c|c|c|c|}
\hline & \multicolumn{2}{|c|}{ ID without ANC } & \multicolumn{2}{|c|}{ ID with ANC } & \multicolumn{2}{|c|}{ ID without PNC-M } & \multicolumn{2}{|c|}{ ID with PNC-M } & \multicolumn{2}{|c|}{$\begin{array}{l}\text { ID without full } \\
\text { vaccination }\end{array}$} & \multicolumn{2}{|c|}{$\begin{array}{l}\text { ID with full } \\
\text { vaccination }\end{array}$} \\
\hline & $2015-16$ & 2005-06 & $2015-16$ & 2005-06 & $2015-16$ & 2005-06 & $2015-16$ & 2005-06 & 2015-16 & 2005-06 & 2015-16 & 2005-06 \\
\hline All India & 12.4 & 11.1 & 87.6 & 50.9 & 25.3 & 9.2 & 74.7 & 76.8 & 48.1 & 31.3 & 65.6 & 61.31 \\
\hline \multicolumn{13}{|l|}{ North } \\
\hline Haryana & 11.7 & 9.0 & 88.3 & 42.8 & 20.5 & 34.4 & 79.5 & 89.4 & 36.4 & 56.5 & 68.5 & 83.84 \\
\hline Himachal Pradesh & 5.8 & 20.6 & 94.2 & 47.7 & 12.4 & 17.3 & 87.6 & 75.9 & 63.5 & 70.9 & 72.0 & 78.08 \\
\hline Jammu \& Kashmir & 6.1 & 11.6 & 93.9 & 60.3 & 15.3 & 10.0 & 84.7 & 82.6 & 57.5 & 56.9 & 77.5 & 72.77 \\
\hline Punjab & 2.3 & 17.2 & 97.8 & 59.4 & 7.3 & 29.2 & 92.7 & 89.1 & 66.1 & 43.0 & 90.4 & 74.98 \\
\hline Rajasthan & 10.7 & 9.3 & 89.3 & 39.3 & 26.7 & 7.4 & 73.3 & 74.9 & 27.9 & 20.4 & 59.2 & 36.96 \\
\hline Uttarakhand & 14.3 & 8.8 & 85.7 & 45.8 & 25.9 & 8.3 & 74.2 & 78.2 & 50.3 & 51.3 & 60.4 & 76.63 \\
\hline \multicolumn{13}{|l|}{ Central } \\
\hline Chhattisgarh & 2.6 & 1.0 & 97.4 & 16.6 & 20.3 & 18.2 & 79.7 & 86.1 & 65.7 & 41.8 & 80.2 & 80.77 \\
\hline Madhya Pradesh & 19.7 & 8.5 & 80.3 & 34.1 & 34.5 & 8.8 & 65.5 & 77.1 & 36.5 & 31.1 & 57.6 & 64.07 \\
\hline Uttar Pradesh & 16.6 & 8.3 & 83.4 & 28.8 & 26.1 & 2.2 & 73.9 & 53.0 & 37.7 & 16.2 & 56.0 & 43.47 \\
\hline \multicolumn{13}{|l|}{ East } \\
\hline Bihar & 36.6 & 11.7 & 63.4 & 38.6 & 38.1 & 4.3 & 61.9 & 59.9 & 51.5 & 28.5 & 66.4 & 49.27 \\
\hline Jharkhand & 15.4 & 4.5 & 84.6 & 30.2 & 36.9 & 4.6 & 63.1 & 67.7 & 56.1 & 29.4 & 65.4 & 58.46 \\
\hline Odisha & 5.2 & 11.6 & 94.8 & 41.4 & 17.1 & 9.4 & 82.9 & 73.1 & 68.6 & 46.2 & 80.2 & 61.79 \\
\hline West Bengal & 7.5 & 10.5 & 92.5 & 47.0 & 25.6 & 14.9 & 74.4 & 73.5 & 79.7 & 57.6 & 86.3 & 73.67 \\
\hline \multicolumn{13}{|l|}{ North-east } \\
\hline Arunachal Pradesh & 31.8 & 11.8 & 68.2 & 49.7 & 49.8 & 2.5 & 50.2 & 66.3 & 24.8 & 22.8 & 50.2 & 44.84 \\
\hline Assam & 7.3 & 5.9 & 92.7 & 32.8 & 27.4 & 1.9 & 72.6 & 50.3 & 31.4 & 27.2 & 53.4 & 51.58 \\
\hline Manipur & 5.2 & 10.6 & 94.8 & 56.3 & 12.7 & 3.5 & 87.3 & 89.4 & 37.3 & 29.5 & 76.5 & 68.59 \\
\hline Meghalaya & 9.9 & 4.4 & 90.1 & 45.6 & 16.6 & 3.4 & 83.5 & 82.2 & 52.4 & 28.7 & 70.0 & 42.82 \\
\hline
\end{tabular}


Table 5. (Continued)

\begin{tabular}{|c|c|c|c|c|c|c|c|c|c|c|c|c|}
\hline & \multicolumn{2}{|c|}{ ID without ANC } & \multicolumn{2}{|c|}{ ID with ANC } & \multicolumn{2}{|c|}{ ID without PNC-M } & \multicolumn{2}{|c|}{ ID with PNC-M } & \multicolumn{2}{|c|}{$\begin{array}{l}\text { ID without full } \\
\text { vaccination }\end{array}$} & \multicolumn{2}{|c|}{$\begin{array}{l}\text { ID with full } \\
\text { vaccination }\end{array}$} \\
\hline & $2015-16$ & $2005-06$ & $2015-16$ & $2005-06$ & $2015-16$ & $2005-06$ & $2015-16$ & $2005-06$ & $2015-16$ & $2005-06$ & $2015-16$ & 2005-06 \\
\hline Mizoram & 5.2 & 27.4 & 94.8 & 74.4 & 22.2 & 6.0 & 77.8 & 77.3 & 27.2 & 33.2 & 56.2 & 54.73 \\
\hline Sikkim & 8.4 & 14.0 & 91.6 & 54.1 & 22.3 & 2.7 & 77.7 & 87.3 & 77.4 & 60.9 & 83.0 & 76.1 \\
\hline Tripura & 7.7 & 14.7 & 92.3 & 60.1 & 25.0 & 8.1 & 75.1 & 52.2 & 54.3 & 30.8 & 55.1 & 66.07 \\
\hline \multicolumn{13}{|l|}{ West } \\
\hline Goa & 2.6 & 27.9 & 97.4 & 95.0 & 6.8 & 16.8 & 93.2 & 80.0 & 0.0 & 69.7 & 87.9 & 79.83 \\
\hline Gujarat & 12.5 & 20.6 & 87.6 & 62.5 & 30.6 & 18.8 & 69.4 & 85.1 & 42.4 & 31.8 & 51.7 & 55.36 \\
\hline Maharashtra & 6.6 & 21.0 & 93.4 & 72.0 & 16.9 & 16.0 & 83.1 & 79.4 & 44.2 & 45.4 & 58.2 & 65.32 \\
\hline \multicolumn{13}{|l|}{ South } \\
\hline Andhra Pradesh & 0.8 & 22.1 & 99.2 & 67.2 & 16.5 & 22.6 & 83.5 & 86.7 & 64.6 & 30.1 & 65.6 & 54.14 \\
\hline Karnataka & 10.6 & 18.9 & 89.4 & 72.8 & 31.8 & 17.2 & 68.2 & 78.5 & 42.3 & 45.5 & 64.2 & 62.07 \\
\hline Kerala & 7.4 & 0.0 & 92.6 & 99.4 & 11.1 & 0.0 & 88.9 & 85.4 & 0.0 & 0.0 & 82.6 & 74.69 \\
\hline Tamil Nadu & 8.4 & 62.5 & 91.6 & 88.9 & 25.4 & 41.0 & 74.6 & 93.0 & 58.2 & 88.2 & 70.7 & 80.07 \\
\hline Telangana & 2.2 & NA & 97.8 & NA & 13 & NA & 86.7 & NA & 61.69 & NA & 70.63 & NA \\
\hline
\end{tabular}


Table 6. Logistic regression odds ratios for institutional delivery (ID), postnatal care for mother (PNC-M) and child full vaccination in India, 2005-06 and 2015-16 and

\begin{tabular}{|c|c|c|c|c|c|c|}
\hline & \multicolumn{2}{|c|}{ OR for ANC with ID } & \multicolumn{2}{|c|}{ OR for ID with PNC } & \multicolumn{2}{|c|}{ OR for ID with full vaccination } \\
\hline & $20015-16$ & 2005-06 & $2015-16$ & 2005-06 & 2015-16 & 2005-06 \\
\hline All India & $4.5(4.4-4.6)$ & $9.0(8.4-9.7)$ & $11.2(10.9-11.5)$ & $33.8(31.9-35.9)$ & $2.3(2.2-2.4)$ & $3.6(3.3-4.0)$ \\
\hline \multicolumn{7}{|l|}{ North } \\
\hline Delhi & $5.2(3.3-8.1)$ & $8.0(4.7-14.0)$ & $6.6(4.3-10.3)$ & $11.4(8.2-15.9)$ & $1.2(0.4-2.8)$ & $2.4(1.3-4.6)$ \\
\hline Haryana & $7.2(6.1-8.5)$ & $7.4(3.7-17.0)$ & $10.1(8.5-11.9)$ & $15.7(10.5-24.0)$ & $4.1(3.0-5.7)$ & $3.8(1.8-8.3)$ \\
\hline Himachal Pradesh & $4.5(3.3-6.0)$ & $2.9(1.8-4.7)$ & $13.5(10.6-17.1)$ & $12.9(8.9-18.8)$ & $1.9(1.2-3.1)$ & $1.4(0.6-3.0)$ \\
\hline Jammu \& Kashmir & $6.8(5.7-8.2)$ & $12.2(6.9-22.9)$ & $38.4(31.3-47.4)$ & $43.7(28.6-67.0)$ & $2.7(2.0-3.7)$ & $2.0(1.1-3.6)$ \\
\hline Punjab & $4.4(2.7-6.9)$ & $6.9(4.0-12.4)$ & $9.5(7.3-12.4)$ & $19.5(13.6-28.1)$ & $3.6(1.5-7.6)$ & $3.9(2.1-7.2)$ \\
\hline Rajasthan & $5.5(4.8-6.2)$ & $6.8(4.6-10.5)$ & $18.1(15.6-21.1)$ & $37.6(26.8-52.8)$ & $3.6(2.8-4.7)$ & $2.4(1.4-4.1)$ \\
\hline Uttarakhand & $4.4(3.7-5.1)$ & $9.0(5.6-14.9)$ & $12.8(10.8-15.1)$ & $40.1(26.3-61.4)$ & $1.4(1.0-1.9)$ & $3.2(1.6-6.4)$ \\
\hline \multicolumn{7}{|l|}{ Central } \\
\hline Chhattisgarh & $4.7(3.7-6.1)$ & $16.6(4.4-139.9)$ & $5.8(5.2-6.6)$ & $32.4(20.7-51.9)$ & $2.5(1.9-3.2)$ & $6.5(2.9-15.9)$ \\
\hline Madhya Pradesh & $3.7(3.4-4.0)$ & $9.4(6.3-14.5)$ & $10.6(9.5-11.7)$ & $50.0(38.0-65.7)$ & $2.2(1.9-2.7)$ & $5.8(3.8-8.9)$ \\
\hline Uttar Pradesh & $3.3(3.1-3.5)$ & $3.9(3.2-4.6)$ & $8.9(8.4-9.4)$ & $31.7(26.1-38.5)$ & $1.9(1.7-2.1)$ & $4.9(3.6-6.6)$ \\
\hline \multicolumn{7}{|l|}{ East } \\
\hline Bihar & $2.5(2.4-2.7)$ & $5.4(4.2-6.9)$ & $11.0(10.1-12.0)$ & $41.4(28.4-60.8)$ & $1.8(1.6-2.1)$ & $2.9(1.8-4.8)$ \\
\hline Jharkhand & $3.3(2.9-3.6)$ & $11.1(6.9-18.6)$ & $6.1(5.5-6.8)$ & $46.3(30.4-70.8)$ & $1.6(1.3-1.9)$ & $3.2(1.7-5.8)$ \\
\hline Odisha & $4.8(4.0-5.7)$ & $6.2(3.7-10.7)$ & $5.0(4.4-5.7)$ & $24.2(17.7-33.2)$ & $1.9(1.4-2.5)$ & $1.9(1.1-3.1)$ \\
\hline West Bengal & $2.8(2.3-3.4)$ & $8.2(4.9-14.2)$ & $8.8(7.4-10.4)$ & $17.0(13.3-21.7)$ & $1.6(1.1-2.4)$ & $2.0(1.3-3.1)$ \\
\hline \multicolumn{7}{|l|}{ North-east } \\
\hline Arunachal Pradesh & $4.3(3.7-4.9)$ & $7.2(4.7-11.3)$ & $15.9(12.6-20.0)$ & $75.2(36.8-167.1)$ & $3.4(2.5-4.8)$ & $2.9(1.3-6.5)$ \\
\hline Assam & $4.5(3.9-5.2)$ & $8.0(5.1-13.0)$ & $13.1(11.6-14.9)$ & $55.1(31.8-100.6)$ & $2.3(1.9-2.9)$ & $2.6(1.4-4.9)$ \\
\hline Manipur & $7.6(6.1-9.4)$ & $9.8(6.2-16.1)$ & $86.4(68.8-108.9)$ & $236.5(145.3-392.7)$ & $4.9(3.6-6.5)$ & $5.0(3.0-8.2)$ \\
\hline
\end{tabular}


Table 6. (Continued)

\begin{tabular}{|c|c|c|c|c|c|c|}
\hline & \multicolumn{2}{|c|}{ OR for ANC with ID } & \multicolumn{2}{|c|}{ OR for ID with PNC } & \multicolumn{2}{|c|}{ OR for ID with full vaccination } \\
\hline & $20015-16$ & 2005-06 & $2015-16$ & 2005-06 & $2015-16$ & 2005-06 \\
\hline Meghalaya & $4.2(3.5-5.2)$ & $18.9(10.2-38.0)$ & $19.7(16.3-23.7)$ & $148.0(79.8-283.0)$ & $2.4(1.8-3.3)$ & $1.7(0.8-3.4)$ \\
\hline Mizoram & $12.6(10.0-16.0)$ & $7.5(4.9-11.6)$ & $20.6(16.5-25.8)$ & $53.7(29.1-104.3)$ & $2.8(1.9-4.0)$ & $2.4(1.1-5.2)$ \\
\hline Nagaland & $5.2(4.4-6.2)$ & $7.5(4.7-12.5)$ & $66.6(48.5-92.8)$ & $150.5(86.4-269.8)$ & $2.7(2.0-3.7)$ & $2.6(1.4-4.6)$ \\
\hline Sikkim & $2.6(1.0-6.0)$ & $7.6(3.3-19.1)$ & $12.2(5.7-28.2)$ & $213.3(93.1-534.9)$ & $1.1(0.02-12.6)$ & $2.3(0.9-5.6)$ \\
\hline Tripura & $5.6(3.8-8.3)$ & $9.4(5.2-17.8)$ & $60.4(32.2-124.6)$ & $12.0(7.0-21.1)$ & $1.6(0.8-3.2)$ & $4.6-(1.9-11.2)$ \\
\hline \multicolumn{7}{|l|}{ West } \\
\hline Goa & $4.1(0.4-49.7)$ & $44.3(15.9-133.5)$ & $7.7(0.6-70.1)$ & $19.8(9.2-46.9)$ & 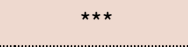 & $1.9(0.4-6.6)$ \\
\hline Gujarat & $3.5(2.9-4.2)$ & $6.3(4.1-10.0)$ & $3.9(3.3-4.6)$ & $24.5(17.6-34.2)$ & $1.8(1.2-2.6)$ & $2.6(1.5-4.4)$ \\
\hline Maharashtra & $4.3(3.5-5.3)$ & $11.1(7.5-16.9)$ & $5.8(4.9-6.9)$ & $17.0(13.3-21.8)$ & $1.9(1.3-2.7)$ & $2.3(1.5-3.4)$ \\
\hline \multicolumn{7}{|l|}{ South } \\
\hline Andhra Pradesh & $6.3(2.3-16.0)$ & $7.5(4.6-12.4)$ & $5.6(4.0-7.9)$ & $25.6(19.0-34.6)$ & $0.9(0.4-1.7)$ & $3.0(1.7-5.4)$ \\
\hline Karnataka & $5.0(3.8-6.4)$ & $11.2(7.4-17.3)$ & $5.4(4.2-7.0)$ & $17.5(13.2-23.1)$ & $1.6(0.9-2.7)$ & $1.9(1.2-3.0)$ \\
\hline Kerala & $6.5(0.11-125.9)$ & $\star \star \star \star$ & $15.2(0.7-897.4)$ & $\star \star \star \star ~$ & $\star \star \star \star$ & $\star \star \star \star$ \\
\hline Tamil Nadu & $5.0(2.5-9.5)$ & $6.1(1.8-19.1)$ & $8.5(4.3-18.0)$ & $20.1(12.8-31.5)$ & $1.3(0.2-6.9)$ & $0.6(0.1-2.4)$ \\
\hline Telangana & $9.1(5.1-16.2)$ & NA & $13.5(9.2-19.8)$ & NA & $1.6(0.7-3.7)$ & NA \\
\hline
\end{tabular}

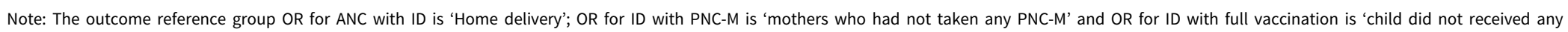
vaccination'.

Values in the parentheses are $95 \%$ confidence intervals.

${ }^{* * \star}$ Estimates could not be generated due to small cell frequencies. 
facilities are less likely to receive postnatal care. A key to improving postnatal care for mothers in these states is increased institutional delivery. The reasons why institutional delivery remains low in some states is an important question in the context of JSY, which directly incentivizes institutional delivery. Previous studies have pointed out that traditions, difficult geographic terrain for transport, fewer health workers and overall poor health system in those states may be related to low institutional delivery rates (Mukherjee \& Roy, 2019).

Surprisingly, institutional delivery did not have a positive impact on postnatal care for children within 2 months of birth. Contrary to expectation, the uptake of postnatal care for children among mothers who had an institutional delivery was lower than among women who did not deliver in a health facility. There could be several reasons for this negative association. It is likely that children delivered at home may have a greater need for postnatal care due to more infections at delivery. It is not clear why some children delivered at health facilities did not receive postnatal care. Whether the poor quality of care women experienced while at the facility during delivery was a deterrent, or if there were out-of-pocket expenditure issues, requires further investigation. There is evidence that the poor have much lower rates of postnatal care for children than their richer counterparts and thus significant inequality in postnatal care uptake in India (Singh et al., 2012).

Full $\mathrm{CoC}$ in India is unlikely to be achieved without significant progress in the utilization of postnatal care by mother and children. This study highlights the need to integrate postnatal care for children with existing demand-side financing programmes such as JSY in the country. The significantly low achievement of complete continuum of care in the north-eastern states signals the need for more focused efforts on most of components of CoC. The one-off cash transfer mechanism of JSY to the women on institutional delivery may require review in the light of emerging evidence of low uptake of postnatal care for children. There is a need to consider a range of JSY implementation options, including staggered payment mechanism whereby critical elements of MNCH are completed before full JSY payment. The JSY progamme should also consider local variations in health system capacity and population characteristics, including traditions, for better coverage of all components of CoC.

Funding. This research was funded by the Department of Biotechnology in India (DBT-BT/IN/DBT-MRC/DFID/18/USM/ 2015-16) and the Medical Research Council (MRC Grant No. MR/N006267/1), UK.

Conflicts of Interest. The authors have no conflicts of interest to declare.

Ethical Approval. The authors assert that all procedures contributing to this work comply with the ethical standards of the relevant national and institutional committees on human experimentation and with the Helsinki Declaration of 1975, as revised in 2008 .

\section{References}

Bhutta ZA, Chopra M, Axelson H, Berman P, Boerma T and Bryce J et al. (2010) Countdown to 2015 decade report (2000-10): taking stock of maternal, newborn and child survival. The Lancet 375(9730), 2032-2044.

Bloom SS, Lippeveld T and Wypij D (1999) Does antenatal care make a difference to safe delivery? A study in urban Uttar Pradesh, India. Health Policy and Planning 14(1), 38-48.

Bryce J, Arnold F, Blanc A, Hancioglu A, Newby H, Requejo J et al. (2013) Measuring coverage in MNCH: new findings, new strategies and recommendations for action. PLoS Medicine 10(5), e1001423.

Chopra M, Daviaud, E, Pattinson R, Fonn S and Lawn JE, (2009) Saving the lives of South Africa's mothers, babies and children: can the health system deliver? The Lancet 374(9692), 835-846.

Guliani H, Sepehri A and Serieux J (2012) What impact does contact with the prenatal care system have on women's use of facility delivery? Evidence from low-income countries. Social Science \& Medicine 74(12), 1882-1890.

IIPS and ICF (2007) National Family Health Survey (NFHS-3), 2005-06. International Institute for Population Sciences (IIPS), Mumbai, India.

IIPS and ICF (2015) National Family Health Survey (NFHS-4), 2015-16. International Institute for Population Sciences (IIPS), Mumbai, India. 
Iqbal S, Maqsood S, Zakar R, Zakar MZ and Fischer F (2017) Continuum of care in maternal, newborn and child health in Pakistan: analysis of trends and determinants from 2006 to 2012. BMC Health Services Research 17(1), 189.

Johar M, Soewondo P, Pujisubekti R, Satrio HK and Adji A (2018) Inequality in access to health care, health insurance and the role of supply factors. Social Science \& Medicine 213, 134-145.

Kerber KJ, De Graft-Johnson JE, Bhutta ZA, Okong P, Starrs A and Lawn JE (2007) Continuum of care for maternal, newborn and child health: from slogan to service delivery. The Lancet 370(9595), 1358-1369

Magadi MA, Zulu EM and Brockerhoff M (2003) The inequality of maternal health care in urban sub-Saharan Africa in the 1990s. Population Studies 57(3), 347-366.

Mohammad MM and Pallikadavath S (2018) How much do conditional cash transfers increase the utilization of maternal and child health care services? New evidence from Janani Suraksha Yojana in India. Economics and Human Biology 31, 164-183.

MoHFW (2018a) Annual Report of Department of Health and Family Welfare 2017-18. Ministry of Health and Family Welfare. URL: https://main.mohfw.gov.in/basicpage/annual-report-2018-19 (accessed $4^{\text {th }}$ October 2020).

MoHFW (2018b) Annual Report of National Health Mission. Ministry of Health and Family Welfare. URL: https://main. mohfw.gov.in/sites/default/files/02\%20ChapterAN2018-19.pdf (accessed $4^{\text {th }}$ October 2020).

Mothupi MC, Knight L and Tabana H (2018) Measurement approaches in continuum of care for maternal health: a critical interpretive synthesis of evidence from LMICS and its implications for the South African context. BMC Health Services Research 18(1), 539.

Mukherjee M and Roy MP (2019) Factors determining institutional delivery in eastern part of India. Tzu-Chi Medical Journal 32(2), 171.

Navaneetham K and Dharmalingam A (2002) Utilization of maternal health care services in Southern India. Social Science \& Medicine 55(10), 1849-1869.

SRS (2011) SRS Special Bulletin on Maternal Mortality in India 2006-2009. Office of the Registrar General of India, Census Commissioner, Government of India, New Delhi, India. URL: https://censusindia.gov.in/vital_statistics/SRS_Bulletins/ Final-MMR\%20Bulletin-2007-09_070711.pdf (accessed $4^{\text {th }}$ October 2020).

SRS (2020) SRS Special Bulletin on Maternal Mortality in India 2016-2018. Office of the Registrar General of India, Census Commissioner, Government of India, New Delhi, India. URL: https://censusindia.gov.in/vital_statistics/SRS_Bulletins/ MMR\%20Bulletin\%202016-18.pdf (accessed $4^{\text {th }}$ October 2020).

Pallikadavath S, Foss M and Stones RW (2004) Antenatal care: provision and inequality in rural north India. Social Science \& Medicine 59(6), 1147-1158.

Rahman MM, Pallikadavath S and Khatoon R (2019) Does shorter postnatal hospital stay lead to postdischarge complications? An instrumental variables approach. Journal of International Development 31(5), 432-471.

Shibanuma A, Yeji F, Okawa S, Mahama E, Kikuchi K, Narh C et al. (2018) The coverage of continuum of care in maternal, newborn and child health: a cross-sectional study of woman-child pairs in Ghana. BMJ Global Health 3(4), e000786.

Singh A, Padmadas SS, Mishra US, Pallikadavath S, Johnson FA and Matthews Z (2012) Socio-economic inequalities in the use of postnatal care in India. PLoS One 7(5).

Tanahashi T (1978) Health service coverage and its evaluation. Bulletin of the World Health Organization 56(2), 295.

Titaley CR, Dibley MJ and Roberts CL, (2009) Factors associated with non-utilization of postnatal care services in Indonesia. Journal of Epidemiology and Community Health 63(10), 827-831.

UNICEF (2020) Monitoring the Situation of Children and Women. URL: https://data.unicef.org/country/ind/ (accessed 17 ${ }^{\text {th }}$ April 2020).

United Nations (2019) Special Edition: Progress Towards the Sustainable Development Goals Report of the Secretary-General. Advanced unedited version. United Nations, New York.

WHO (2016) Recommendations on Antenatal Care for a Positive Pregnancy Experience. URL: https://www.who.int/ publications/i/item/9789241549912 (accessed 4th November 2020).

WHO, UNFPA, UNICEF, ICM, ICN, FIGO and IPA (2018) Definition of Skilled Health Personnel Providing Care During Childbirth: The 2018 Joint Statement by WHO, UNFPA, UNICEF, ICM, ICN, FIGO and IPA. URL: file://C:/Users/ Administrator/Desktop/WHO-RHR-18.14-eng.pdf (accessed 4th October 2020).

Cite this article: James KS, Mishra US, Rinju, and Pallikadavath S (2022). Sequential impact of components of maternal and child health care services on the continuum of care in India. Journal of Biosocial Science 54, 450-472. https://doi.org/10.1017/ S002193202100016X 